\title{
Effect of Diet on Evolutionary Obstetrics
}

\author{
Satyajit Patra ${ }^{1 *}$ and Shakti Sagar ${ }^{2}$ \\ ${ }^{1}$ Associate Professor, American International Medical University, St. Lucia \\ ${ }^{2}$ Institute of Medical Sciences and Sum Hospital, Bhubaneswar, India
}

Received: 眥October 10, 2018; Published: 㘹October 15, 2018

*Corresponding author: Satyajit Patra, Associate Professor, American International Medical University, St. Lucia

\section{Opinion}

Diet and health are both related directly to the reproductive functions of a female in that nutrient intake effects exactly what hormones are produced and at what amounts. According literature women of Western societies produce more progesterone and estradiol from their ovaries leading to high rates of breast cancer in the West [1]. Another facet to the Western diet is foods that are rich in sugar thus contributing to the blood sugar level and ultimately affecting resistance to insulin. This resistance to insulin, which is called diabetes, may lead to many problems of the reproductive function of women. Obesity, insulin resistance, and hyperinsulinemia are all common of women in the West and lead to oligomenorrhea, amenorrhea, and chronic anovulation [2]. Regions pay big role into nutrition in the sense that different areas have abundance of different types of foods, a bulk of North America simply gets absorbed into the "western" diet, meaning increased intake of unhealthy food due to increased availability of fast food. Since these female populations are adopting nutritious lifestyles leading to obesity, insulin resistance, and hyperinsulinemia, these newly developing populations have women who are unable to reproduce as well, thus making this "developing society" not "develop." The current research is supported with case studies demonstrating insulin levels, SHBG, and testosterone levels of women who are of south Asian descent living in affluent societies such as the United Kingdom [3]. The evidence provided portrayed that though there were two type of women living in the same society, women from south Asia that were adopting the new Western lifestyles were more susceptible to having high levels of insulin and insulin resistance, thus proving that the societies that are westernizing is leading to reproductive failure of the women. What this portrays is that high levels of obesity, insulin resistance, and insulin itself leads populations in transition to have reduced fecundity in women and based on the examples provided, it is a logical conclusion [4].

Another, "purposeful" way of preventing pregnancy is to take oral contraceptives or using contraceptives altogether before having sexual intercourse. There are many different types of ways a woman who is sexually active can prevent pregnancy. The most recent type of contraception is the menstrual-suppressing oral contraceptives which lead to virtually no menstrual cycle or a very consistent menstrual cycle like one every 3 months [5]. The basis of the menstrual cycle is avoided because of the menstrualsuppressing oral contraceptives. The main reason this happens is to procure sexual development and gain levels in estrogen and progesterone. There are two general standpoints on whether these contraceptives should be taken: the fact that the menstrual cycle is physiologically tolling, or menstruation is energetically less costly than maintain the endometrium between ovulations [6]. There are many different hypotheses present, after these standpoints are mentioned, which talk about what menstruation can do and why it is there. These hypotheses are that menstruation was an evolutionary byproduct, it aids in pathogen removal, it weeds out defective embryos, and it advertises fertility. How women feel about menstruation also would aid in decisions on whether to use contraception or not. According to the surveys, women are inadvertently split close to even in that some women feel they need the period and some feel that they should take oral contraceptives to ease the pain and reduce bleeding that occurs [7]. There are various pros and cons when considering oral contraceptives, so it is completely a woman's choice on to take one or not. The menstrual cycle is neither beneficial nor deleterious when compared with women taking contraception, thus leaving the argument open ended on whether taking these contraceptives are viable. Poor diet garners an overall unwanted experience while contraception is used for the sole purpose of deterring pregnancy; these are two of the few ways that women are preventing pregnancies [8].

\section{References}

1. Wiseman RA (2001) Lifestyle, progesterone, and risk of breast cancer. Causal association between progesterone concentrations and breast cancer has not been shown. BMJ 323(7319): 1002.

2. Barthelmess EK, Naz RK (2014) Polycystic ovary syndrome: current status and future perspective. Frontiers in bioscience 6: 104-119.

3. Heald AH, Patel J, Anderson SG, Vyas A, Rudenski A, et al. (2007) Migration is associated with lower total, but not free testosterone levels in South Asian men. Clinical endocrinology 67(5): 651-655. 
4. Wilcox G (2005) Insulin and insulin resistance. The Clinical biochemist Reviews 26(2): 19-39.

5. Nappi RE, Kaunitz AM, Bitzer J (2016) Extended regimen combined oral contraception: A review of evolving concepts and acceptance by women and clinicians. The European journal of contraception \& reproductive health care 21(2): 106-115.

6. Maybin JA, Critchley HO (2015) Menstrual physiology: implications for endometrial pathology and beyond. Human reproduction update 21(6) 748-761.

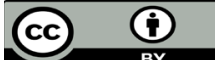

This work is licensed under Creative Commons Attribution 4.0 License

To Submit Your Article Click Here:

Submit Article

DoI: 10.32474/IGWHC.2018.03.000151
7. Maybin JA, Critchley HO (2016) Medical management of heavy menstrual bleeding. Women's health 12(1): 27-34

8. Kopp Kallner H, Thunell L, Brynhildsen J, Mia Lindeberg, Kristina Gemzell Danielsson (2015) Use of Contraception and Attitudes towards Contraceptive Use in Swedish Women-A Nationwide Survey. PloS one 10: e0125990.

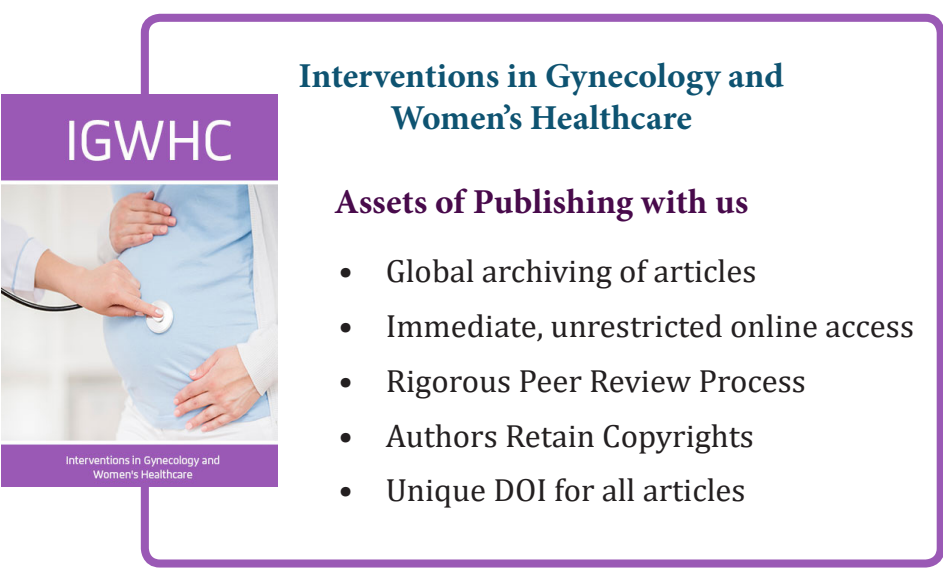

